\title{
Les Cheminots dans l'histoire sociale de la France. Une relecture à quarante ans de distance
}

Railwaymen in French social history: Reading the book again after 40 years

Michel Pigenet

\section{OpenEdition}

Journals

Édition électronique

URL : https://journals.openedition.org/rhcf/94

DOI : $10.4000 /$ rhcf. 94

Éditeur

Rails \& histoire

Édition imprimée

Date de publication : 1 décembre 2007

Pagination : 73-76

ISSN : 0996-9403

Référence électronique

Michel Pigenet, «Les Cheminots dans l'histoire sociale de la France. Une relecture à quarante ans de distance », Revue d'histoire des chemins de fer [En ligne], 36-37 | 2007, mis en ligne le 10 mai 2011 consulté le 22 avril 2022. URL : http://journals.openedition.org/rhcf/94 ; DOI : https://doi.org/10.4000/ rhcf.94

Tous droits réservés 


\title{
Les Cheminots dans l'histoire sociale de la France. Une relecture à quarante ans de distance
}

\author{
Michel Pigenet \\ Professeur à l'université de Paris I - Panthéon-Sorbonne
}

\begin{abstract}
À sa manière, la couverture résume l'ambivalence de l'ouvrage*. Audacieux, le titre annonce l'ambition d'une approche de la profession cheminote évaluée à l'aune de l'histoire nationale. Revendiqué par la Fédération nationale des cheminots CGT à l'origine de la « commande », le livre parait aux Éditions sociales, la principale des maisons liées au parti communiste. Le rôle de Joseph Jacquet, rédacteur unique, est paradoxalement atténué par la « direction » qu'on lui reconnait à la tête de l'équipe dont les recherches ont nourri le livre. Le délicat agencement du collectif et de l'individuel se retrouve dans le montage qui forme le fond de la couverture. À travers la figure tutélaire de Pierre Sémard et les silhouettes de saboteurs, l'illustration évoque la Résistance ferroviaire, choix exemplaire dans tous les sens du terme, de nature à conforter l'image héroïque et patriote de la corporation, mais quelque peu réductrice, sinon contradictoire, avec le projet d'une « histoire sociale » plus que centenaire.
\end{abstract}

Le choix souligne à quel point « l'épopée glorieuse » de la Seconde Guerre mondiale, référence structurante de la CGT des années 1960, constitue le passage obligé de tout rappel du passé. Le plus inaccessible, aussi, à une démarche véritablement historienne avec ce que cela suppose de recul critique. L'omniprésence des acteurs de la période - Jacquet compris - à la tête de la fédération y porte d'autant moins que chacune des épreuves survenues depuis la Libération - épuration syndicale, scissions, affrontements de la guerre froide - exacerbe la propension à jeter la suspicion sur le comportement patriotique des concurrents et de la hiérarchie. Le vocabulaire se ressent, bien au-delà des années sombres, de certitudes militantes promptes aux jugements de valeur, qu'il s'agisse d'apprécier définitivement la signification d'un événement ou de déceler chez les « autres » une tendance récurrente à rester «à la traîne ", à céder, sinon à trahir. À édulcorer ou à masquer, aussi, les échecs - l'automne 1947 - et les épisodes difficiles - le recul électoral de la fédération après les événements de Hongrie... En cela, Les

* Joseph Jacquet, et al., Les Cheminots dans l'histoire sociale de la France, Paris, Éditions sociales, 1967. 
Cheminots... s'inscrivent dans la tradition cégétiste d'une histoire normative, riche en «leçons » et récits manichéens, dont la seconde édition, la même année, de l'Esquisse de l'histoire de la CGT offre le modèle. Au reste, la préface de Benoit Frachon conclut sur l'intérêt et l'utilité de l'ouvrage, contribution à une « histoire vraie », attentive à « donner leur sens aux événements », à «les interpréter selon la dynamique de la vie et des luttes ». Sur la lancée, le tout nouveau président de la CGT oppose le texte livré par Jacquet aux travaux d'historiens ignorants des réalités de la lutte des classes ou, pire, aux « jongleries » de ceux qui, en rupture avec le mouvement ouvrier, poursuivent de leur « haine » leurs anciens camarades. Aucun nom n'est cité, mais comment ne pas songer à Annie Kriegel dont les thèses récentes s'attardent sur les grèves de 1920 ? Le texte ne renoue pas, au demeurant, avec le scepticisme brutal par lequel Frachon confiait, en privé, quelques années auparavant : «l'histoire, on lui fait dire ce qu'on veut. » À bien le lire, il s'écarte plutôt de cette conception pour approuver une approche attentive aux données économiques et sociales. Adhésion encore fragile, sans doute, si l'on considère la prééminence du regard militant tourné vers les grèves et les questions d'organisation, mais caution de poids aux aspects inhabituels de la démarche.

Loin de s'en tenir à une chronique des luttes revues à travers les commentaires des auteurs autorisés ou tirés de la presse syndicale, l'ouvrage témoigne d'indéniables préoccupations méthodologiques. À l'exception signalée de ceux de la préfecture de Police, les fonds consultés couvrent l'ensemble des archives accessibles : syndicales, bien sûr, mais aussi dépôts publics, avec mention particulière pour les séries $\mathrm{F}^{7}$ et $\mathrm{F}^{12}$ des Archives nationales et les cartons issus des compagnies de chemin de fer. Les bibliothèques et centres fréquentés montrent un souci d'exhaustivité que confirme l'éclectisme de bon aloi d'une bibliographie où Benoît Frachon, Jean Bruhat, Robert Brécy, Jean Dautry, Emile Tersen... côtoient les Bonnefous, Gérard Adam, Bertrand Gille, Annie Kriegel, Maxime Leroy, René Rémond, etc. L’hommage rendu aux encouragements prodigués en ce sens par des « camarades dont le métier est d'être historien » cite nommément Jean Maitron, spécialiste de l'anarchisme et du mouvement ouvrier, extérieur au premier cercle des historiens «amis » de la CGT. Idéologiquement, l'affaire ne va pas de soi. Elle suppose, en outre, une formation assurément accélérée aux techniques et rigueurs d'une recherche à laquelle les militants n'ont jamais été préparés. À cette fin, Joseph Jacquet veille à s'entourer de jeunes cheminots lyonnais qu'il connait bien, gage de cohésion et de dynamisme. Prudence et fierté mêlées, l'équipe récuse toute prétention 
à se mesurer aux professionnels de l'histoire mais affiche une volonté de s'approprier le passé de la corporation : par quoi l'ancienne tradition cégétiste d'autonomie croise les expériences à venir de workshop history. Deux années ne sont pas de trop pour consulter et maitriser les sources et la littérature traitant du sujet, établir un plan et rédiger quelques 300 pages d'un texte dont on a pu dire qu'« il sonne juste ».

Force est de constater que l'initiative ne sera guère couronnée de succès. Le tourbillon social du printemps 1968 ne pouvait que perturber la campagne de promotion militante. L'explication ne convainc pourtant qu'à moitié. Au plus fort des grèves, les confrontations de la période se jouent aussi sur le terrain des faits historiques et des héritages symboliques. Pour plusieurs années, les événements stimulent une curiosité sans précédent pour le passé du mouvement ouvrier à l'origine d'une production éditoriale abondante et disparate. Le parti communiste prend toutefois l'avantage sur la CGT qui, hormis la diffusion de son Esquisse, manuel commode dont le tirage pour sa seconde édition atteint 80000 exemplaires, semble lui abandonner le front d'une histoire aux trop lourds enjeux idéologiques. Ce qui n'empêche pas nombre de syndicalistes de contribuer aux activités des commissions d'histoire du PCF et de signer quelques-uns des livres publiés dans ce cadre. Plus personnels, aux frontières des mémoires, ou associant chercheurs et militants autour de problématiques mieux définies, les ouvrages en question rompent avec l'entre-deux historiographique des Cheminots dont le style et le contenu accusent l'âge pour en effacer les audaces.

Aussi bien est-ce sur d'autres bases et perspectives que la CGT manifeste son intention, en 1981, de « remettre sur ses rails » l'apprentissage de l'histoire et faire valoir la compétence des syndicats à traiter certains de ses aspects. Les expériences et les coopérations engagées par les cheminots des années 1960 ne sont pas étrangères, toutefois, à la démarche que propose Georges Séguy, sur le départ du secrétariat général de la confédération. Il n'est pas moins significatif qu'un Centre d'histoire du mouvement syndical des travailleurs de la région RhôneAlpes soit créé à Villeurbanne, en octobre 1981, sous la responsabilité de Joseph Jacquet, avant même la constitution officielle de l'Institut CGT d'histoire, dont il assure la vice-présidence. La formation d'un Institut fédéral des cheminots réclame plus de temps et n'intervient qu'au lendemain du décès de Jacquet, en 1998. L'éditorial du premier bulletin s'inscrit dans la continuité des objectifs d'hier: " nous approprier notre propre histoire sociale et (de) la faire à partir de ceux qui l'ont construite et vécue ». Le projet de se « servir de cet héritage pour les combats que nous menons aujourd'hui » n'exclut pas le concours de 
spécialistes, telles cette historienne et cette sociologue auxquelles on confie la préparation d'une enquête sur 1968, tandis que l'institut appuie la collaboration de ses membres à la réalisation d'une version cheminote du Dictionnaire du mouvement ouvrier Maitron. L’âge des retraités qui, pour la plupart, l'animent, tranche, cependant, avec la jeunesse des militants rassemblés en 1965. Une certaine nostalgie attise enfin, signe des temps, le sentiment d'une identité professionnelle et syndicale menacée. 